\title{
Association Between Mean Arterial Pressure and Delirium in Postoperative Critically III Patients
}

\author{
Kamal Maheshwari, Gausan Bajracharya, Ashish Khanna, Guangmei Mao, Silvia Perez Protto, Andrea Kurz, \\ Alparslan Turan, Daniel Sessler MD \\ Outcomes Research Department, Anesthesiology Institute, Cleveland Clinic, Cleveland, United States
}

\section{Cleveland Clinic}

\section{Introduction}

Figure 1. Flow chart

Postoperative delirium is common, with a reported incidence of $11-43 \%^{1}$, and is associated with significant morbidity and $\operatorname{cost}^{2,3}$. The extent to which perioperative hypotension contributes to delirium in critically ill patients remains poorly understood. The relationship is of considerable interest because hypotension is one of the very few potential correlates of critical care delirium that is modifiable and thus amenable to intervention.

\section{Methods}

We included 908 postoperative patients admitted directly to the intensive care unit from the operating room(Fig 1). A Cox proportional hazard survival model was used to assess the association between the amount of intraoperative hypotension, which was measured as the time-weighted average of MAP lower than $65 \mathrm{mmHg}$, and delirium in ICU, adjusting for potential confounding variables. As for blood pressure during ICU stay, we used Cox model with the lowest MAP on each intensive care day as a time varying covariate to assess its association to delirium, adjusted for confounders and intraoperative amount of hypotension. (Table 1)

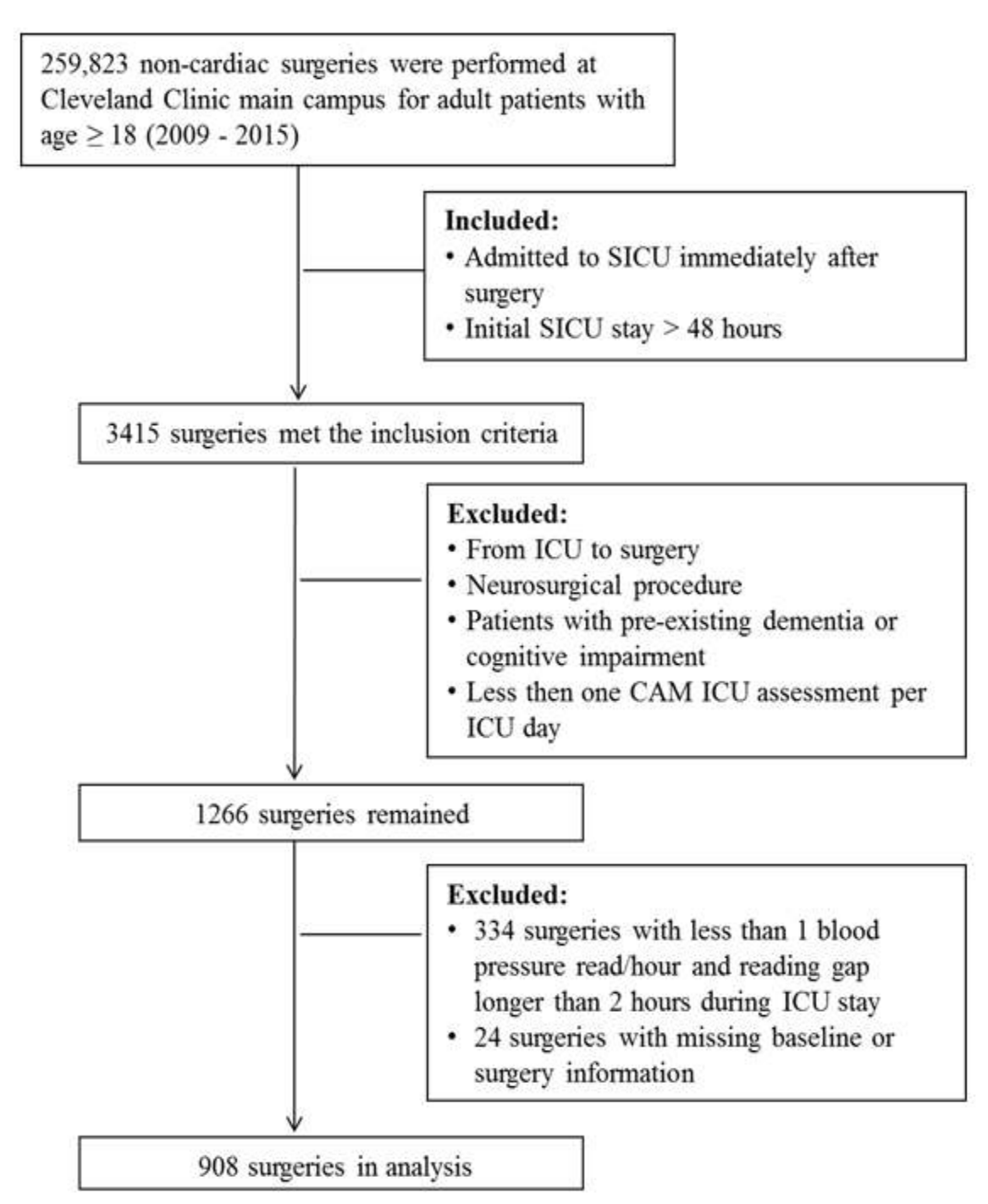

\section{Results}

$316(34.8 \%)$ patients had delirium within 5 postoperative days in ICU. Intraoperative hypotension was moderately associated with higher odds of postoperative delirium (Figure 2). The adjusted hazard ratio associated with one unit increase in TWA of MAP $<65 \mathrm{mmHg}$ was 1.10 (95\% Cl: 1.01, 1.20; $\mathrm{P}=0.029)$. For postoperative blood pressures, a $10-\mathrm{mmHg}$ reduction in the lowest MAP on each day during ICU stay was significantly associated with a higher hazard of delirium, with an adjusted hazard ratio 1.16 (95\% $\mathrm{Cl}: 1.07,1.26 ; \mathrm{P}<0.001)$.

\section{Conclusion}

Both intraoperative and postoperative hypotension were associated with delirium in postoperative critical care patients. Whether the relationship is causal remains to be determined.

Figure 2. Associations of intraoperative TWA of MAP $<65 \mathrm{mmHg}$ and lowest MAP on each day during ICU stay to delirium in ICU.

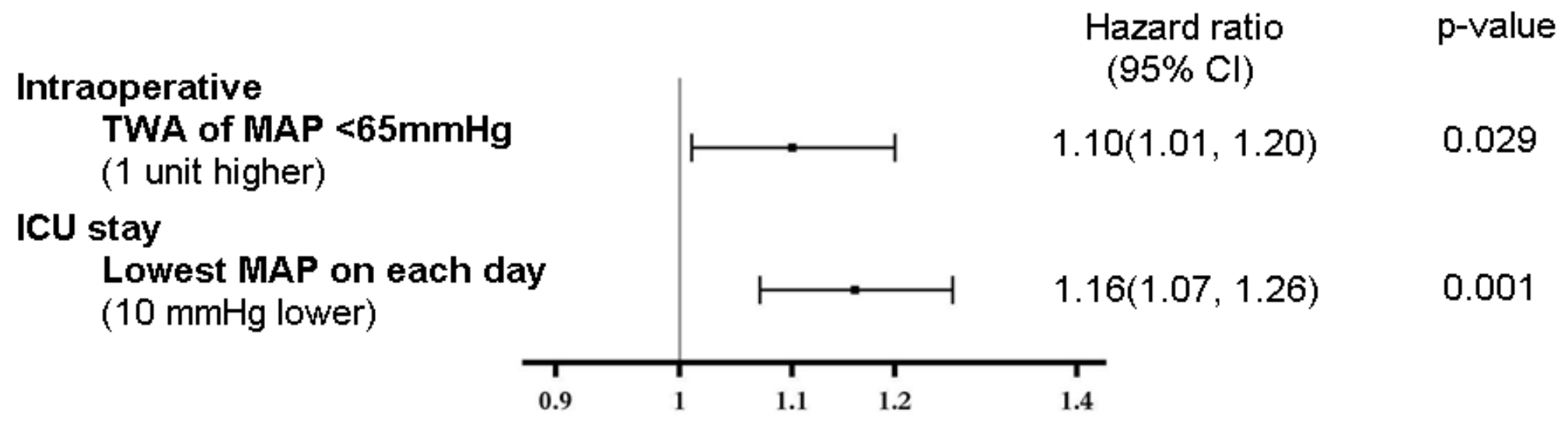

Table 1. Patient characteristics and surgery information

\begin{tabular}{|c|c|c|}
\hline Factor & $\begin{array}{l}\text { Without delirium } \\
\qquad(\mathrm{N}=592)\end{array}$ & $\begin{array}{l}\text { With delirium } \\
(\mathrm{N}=\mathbf{3 1 6})\end{array}$ \\
\hline Age - year & $60 \pm 14$ & $64 \pm 13$ \\
\hline Gender - female \% & $261(44)$ & $146(46)$ \\
\hline Race - white\% & $487(82)$ & $258(82)$ \\
\hline \multicolumn{3}{|l|}{ ASA status } \\
\hline 2 & $22(4)$ & $8(3)$ \\
\hline 3 & $270(46)$ & $138(44)$ \\
\hline 4 & $296(50)$ & $168(53)$ \\
\hline 5 & $3(0.5)$ & $2(0.6)$ \\
\hline Charlson comorbidity index & $3[1,6]$ & $4[2,5]$ \\
\hline \multicolumn{3}{|l|}{$\begin{array}{l}\text { History of }-\% \\
\end{array}$} \\
\hline Depression & $87(15)$ & $59(19)$ \\
\hline Alcohol abuse & $30(5)$ & $29(9)$ \\
\hline Vision impairment & $10(2)$ & $8(3)$ \\
\hline Hearing impairment & $11(2)$ & $9(3)$ \\
\hline Use of benzodiazepines & $156(26)$ & $112(35)$ \\
\hline Surgery duration - minute & $511[321,678]$ & $458[247,654]$ \\
\hline Emergency surgery - \% & $119(20)$ & $98(31)$ \\
\hline \multicolumn{3}{|l|}{ Surgery type $-\%$} \\
\hline Organ transplant & $136(23)$ & $79(25)$ \\
\hline On digestive system & $181(31)$ & $112(35)$ \\
\hline On musculoskeletal system & $79(13)$ & $44(14)$ \\
\hline Other & $195(33)$ & $81(26)$ \\
\hline \multirow{3}{*}{$\begin{array}{l}\text { Blood loss - } \mathrm{mL} \\
\text { Transfusion - } \mathrm{mL} \\
\text { Intraoperative opioid as iv morphine } \\
\text { equivalent - } \mathrm{mg}\end{array}$} & $700[250,2350]$ & $500[100,3250]$ \\
\hline & $660[0.0,1946]$ & $667[0.0,2697]$ \\
\hline & $37[20,70]$ & $25[15,50]$ \\
\hline
\end{tabular}

